TP Periodica Polytechnica Mechanical Engineering

62(4), pp. 269-276, 2018

https://doi.org/10.3311/PPme.11877

Creative Commons Attribution (i)

RESEARCH ARTICLE

\section{Prospects of Using Hydrodynamic} Cavitation for Enhancement of Efficiency of Fluid Working Medium Preparation Technologies

\author{
Anatolii Fesenko ${ }^{1}$, Fatyma Yevsiukova ${ }^{1}$, Yevheniia Basova ${ }^{1 *}$, \\ Maryna Ivanova ${ }^{1}$, Vitalii Ivanov ${ }^{2}$ \\ Received 25 December 2017; accepted after revision 05 June 2018
}

\begin{abstract}
In this article a hardware estimation procedure and optimization of parameters of working fluid cavitation processing are proposed. Here the basic aspects of preparation efficiency and using of water-fuel emulsion are reviewed. An example of estimation of energy parameters of hydrodynamic activator operation in obtaining water-fuel emulsion is supplied.
\end{abstract}

\section{Keywords}

emulsion, cavitation, hydrodynamic device, dispersant

\footnotetext{
${ }^{1}$ Department of Technology of Mechanical Engineering and Metal-Cutting Machine Tools, Faculty of Manufacturing Engineering,

National Technical University "Kharkiv Polytechnic Institute", 61002 Kharkov, 2 Kyrpychova str., Ukraine

${ }^{2}$ Department of Manufacturing Engineering, Machines and Tools, Faculty of Technical Systems and Energy Efficient Technologies, Sumy State University, 40007 Sumy, 2 Rymskogo-Korsakova St., Ukraine

*Corresponding author, e-mail: e.v.basova.khpi@gmail.com
}

\section{Introduction}

High requirements to reduction of energy content and efficiency enhancement of state-of-the-art technologies in connection with the provision of environmental parameters of the processes suggests selection of the most effective scientific achievements and set challenges to contemporary science of searching new approaches to problems of different industries. Among them, the most important groups of activities can be identified: energy upgrading, intensive energy conservation and efficient waste recovery.

Efficiency enhancement, energy conservation and environmental safety problems set to modern science and industry the problems of searching new ways of influencing the processed objects and provision of such technologies with rational hardware. One of the trends is to intensify the processes occurring in the working fluid with introduction into working fluid of additional forms of energy or redistribution of the input energy to activate and receive the necessary effect with less input [1].

For intensification of chemical and mass transfer processes in reacting systems liquid - gas, liquid - liquid and liquid solid substance methods of cavitation impact are used [2-5]. The greatest effect is achieved in the processes of chemical synthesis controlled by mass exchange, since the kinetic limitations are sharply reduced [6]. Emulsifying, dispersing, homogenizing, mixing, evaporation and condensation, degassing and saturation - are the main stages of technological processes in various industries: oil refining, petrochemical, chemical, pharmaceutical, microbiological, food, paint and other industries that may be intensified by using cavitation impact [7-8].

Currently, in various industries the increasing application of hydrodynamic devices, due to which the conditions of cavitation in a fluid flow are created. For example, the new non-conventional machining method known as Bubble Machining is based on the process of cavitation [9]. The effect of ultrasound on generating and controlling the cavitation bubble of the grinding fluid during ultrasonic vibration honing was investigated [10]. In paper [11] a novel sharp interface approach for modeling the cavitation phenomena in incompressible viscous flows is described. 
This ensures dispersion, homogenization, activation, acceleration of chemical reactions, heating of the working fluid [12-13]. These devices, depending on the technological purpose and embodied ideas of their authors, have different designs, but are designed for energy impact on the medium in the working area of plants.

The idea of using the cumulative effect of collapsing cavitation bubbles for the intensification of technological processes has led to creation of various structures of hydrodynamic cavitation devices.

Hydrodynamic cavitation is caused by a strong local decrease of pressure owing to high-velocity fluid flow. With increasing velocity of the fluid above the critical bubbles of gas or vapor are formed in fluid that, when getting into a low pressure area acquires ability of an unlimited growth. Getting into the region of high pressure, cavitation bubbles sharply collapse. Thus, expansion and contraction of cavitation bubble is a kind of transformation of power. In the final stage of collapse of cavitation bubbles there appear powerful short pulses of pressure. The speed of closing of the cavity bubbles under certain conditions increases to supersonic, that gives rise to a spherical shock wave, a significant local increase in temperature and intensive emission of energy at the moment of collapse of the cavity. During the collapse the gas-vapor mixture reaches temperatures above critical and is adiabatically compressed to high pressures. Gas pressure inside the cavity reaches a very large value - tens and hundreds of thousands of atmospheres [14].

Technologies using cavitation are used for preparation of fuel mixtures, for making and recovering cutting fluids, for preparation of food mixtures and disinfection of water, for acceleration of chemical processes etc.

\section{Theoretical fundamentals}

\subsection{Preparation of fuel emulsions}

Use of diesel fuel, fuel oil, rapeseed and shale oil as a fuel for various power plants can be effective after pretreatment for homogenization, removing of water lenses and fragmentation thickened inclusions. Only in this case its stable combustion can be provided $[15,16]$.

At present, sufficient experience in the use of hydrodynamic devices for treatment of fuel oil, diesel and other fuels in their preparation for burning in various energy plants has been gathered. However, the data on other fuels are not complete. In particularly, the data on cavitational treatment of shale oil are not provided. Though, this area is very promising.

Below the materials showing the efficiency of pre-cavitational processing of fuel on the examples of the use of fuel oil and various fuel emulsions are given.

Presence of water in combusted fuel oil at its non-uniform distribution in the form of large drops, lenses, etc. necessarily entails a fall in boiler unit efficiency due to non-uniformity of combustion, added by additional consumption of fuel for water evaporation [16, 17]. Even during combustion of fuel oil with the conditioned water content (up to $5 \%$ ) average operational excess air coefficient is found to be above the optimal by $5.5 \%$ and average operational boiler unit efficiency drops by $0.5-1.1 \%$. When water content of fuel oil is $10-15 \%$ the efficiency of the boiler unit is reduced by at least 2.0-3.5\%. Thus, efficient use of water-bearing fuel oil is only possible under uniform spatial distribution of water in a fine-dispersed form throughout the whole volume, which is achieved by cavitation effect.

Comparative data about combustion of emulsified fuel and anhydrous show that emulsified fuel burns much faster than anhydrous, and burning of water-fuel emulsions in boilers and furnaces saves 10-15\% fuel oil, compared to combustion of the pure fuel.

Water-fuel emulsion - is a fundamentally new type of synthetic fuel, which differs from specific fuel oil by combustion and heat transfer features. This is a dispersed system of two mutually insolubles, one of which (water) in the form of tiny droplets uniformly distributed in the other (oil). When getting into the furnace a drop of water, surrounded by a layer of oil, instantly begins to boil, breaking the oil into tiny particles (a phenomenon of micro explosion), which, when coming in contact with the fed oxidant (air), are burnt. With this the process of burning fuel oil intensifies, increasing the speed and completeness of its combustion. Thus, water in water-oil emulsions is a catalyst, improving and accelerating the process of fuel burning. The greatest economic effect and the simultaneous reduction of toxic components in gas emissions are provided by addition of about $10 \%$ to $15 \%$ of water into fuel.

The National Technical University "Kharkov Polytechnic Institute" in association with the North-East Research Center of the National Academy of Sciences of Ukraine, has created a number of highly efficient flanged rotary-cavitation dispersants such as "DF", allowing to obtain emulsion dispersion 2-20 microns and water content 5-15\%. Emulsion is homogeneous and stable. The plant capacity makes 5 to $20 \mathrm{t} / \mathrm{h}$, water content is automatically maintained in the range of 5-15\%

Experience in operating our plants has shown reliability and efficiency of systems for preparation of water-fuel emulsions. Plants of this type are easily to install in existing boiler room. Wastewater containing used technical oils and cutting fluids can be used as an aqueous emulsion. A dispersant in the existing boiler room can be arranged as shown in Fig. 1.

Thus, burning of fuel oil (or other fuel) can be performed by the usual scheme (solid line). For preparation of WFE (water-fuel emulsion) additional equipment is installed (thin line), which includes a mixer, dispersant, hydrometer, water and WFE tanks. For preparation of WFE oil is fed to the mixer, where water is added. Here it is premixed. Cavitation processing is performed in the disperser, and then passes through the hydrometer and enters the high pressure pump. Control of water supply is done automatically from data obtained from the hydrometer. This process flow 


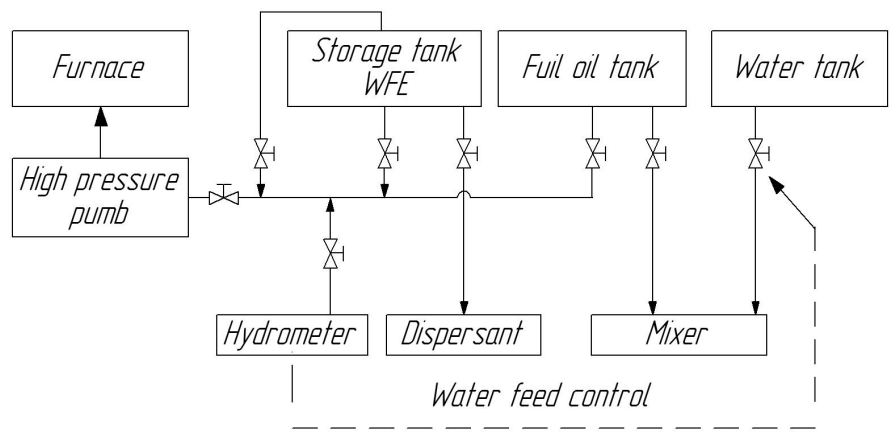

Fig. 1 Process flow sheet of the dispersant in the existing boiler room

sheet enables accumulation of WFE with subsequent use, either directly or after further processing in the dispersant.

Another important factor characterizing the efficiency of water-emulsion boiler-furnace processes is efficiency enhancement and durability of fuel equipment. According to some foreign data, excessive fuel consumption is caused by contamination of boiler heating surfaces by soot and coke particles that may exceed 30-35\%. During combustion a part of emulsion droplets reaches heating surfaces and explodes on them, which contributes not only to prevention of deposits, but also cleans the surfaces from old soot formations.

In addition, one of the factors that determine the effectiveness of WFE in boiler-furnace processes is a possibility to solve a number of environmental problems on their base. Firing reduces the discharge of WFE in gas emissions of $\mathrm{NO}_{x}$ (by $50 \%$ ), by 3-4 times reduces the emission of soot deposits, reduces the output of $\mathrm{CO}$ on average by $50 \%$, benzo(a)pyrene by 2-3 times, etc.

To the problems complicating the environmental situation can be attributed a continuous accumulation of hundreds of thousands of tonnes of ballast water containing oil products. Their source is the industrial enterprises, marine and river ships. In particular, the existing current system of fuel oil unloading from rail tank leads to significant flooding of oil in storage (up to $10 \%$ by weight). At the same time, according to regulatory documents water content for combustion of fuel oil shall not exceed $0.3-1 \%$. In traditional terms preparation of fuel oil for combustion at present is limited mainly by two operations: dehydration and heating. Measures for oil dehydration by water evaporation are energy-intensive and lead to loss of volatile components of fuel. Dehydration is mainly performed by settling, in order to prevent the uncontrolled access of water into the furnace, the consequences of which are difficult to predict. Separation of oil-water phase in storage tanks, requires a sufficiently long time and is inefficient due to closeness of fuel oil and water densities. The problem of disposal or treatment of such water can not be solved by chemical and biological methods, because they require large additional space, capital and operating expenditures. Polluted water is often dumped into a common sewer without proper purification, which contradicts the environmental requirements. Using such water for creation of WFE can remove the whole range of problems. The greatest environmental benefits of recycling contaminated water by organic products are realized at the level of the aqueous phase, up to $50 \%$.

Cavitation plant allows obtaining a high-calorie fuel with addition of water, oil, oil sludge, pyrolysis fuel $[18,19]$. Application of hydrodynamic dispersant allows producing multi-component homogenized, micro-emulsion fuel with calorific value up to $10-14 \mathrm{kcal} / \mathrm{kg}$, representing the resilient emulsion.

The economic effect of use of WFE [20] is achieved by: reducing the loss of energy and resources for auxiliary needs of boiler rooms, reducing and sometimes excluding the costs related to collection, treatment, storage, and removal of waste oil and oil-containing liquids, return to the cycle, i.e. afterburning of up to 8-15\% of previously unused waste oil disposed to the environment and fuel hydrocarbon of fuel oil bearing water, regular fuel savings up to $12 \%$, reduction of maintenance costs of the boiler room, using cheap substandard fuel oil (including crude oil).

\subsection{The development and use of rotary equipment}

Analyzing cavitation plants and methods of energy transfer to working fluids, when activating processed medium two process schemes of the devices can be identified: as passive, when energy is transmitted to the flow upstream before entering the plant, and active, creating a flow in the plant [14, 21].

Among passive plants are such as static, containing no moving parts in a system of formation of fluid flows. Mechanical activation of emulsion in these plants is a result of interaction of a moving fluid with the fixed elements of the working chamber, made and arranged in such a way that most effectively generates a stream with a pronounced nonlinearity of a spatial distribution of instantaneous velocities of the liquid, both in magnitude and in direction. For this purpose, the labyrinth, holes, narrow slits in a special heads are used, etc. In this case, the higher the requirements for dispersion and homogeneity of the emulsion, the higher the power potential should have the current in front of cavitators. Such schemes should include external pressure device, which ensures high-speed to the processed medium.

Dynamic plants can be classified as active plants, in which mechanical activation is due to impact on liquid of moving parts, which rotating, vibrating or completing more complicated motion [14]. In rotary plants energy is received by emulsion in the apparatus due to centrifugal forces that arise in cavities of rotating impellers (rotors). In this case, the intensity of treatment is defined as the geometrical parameters of working area and rotor speed. Such plants can perform and function as transfer pumps that usually reduce the energy consumption of the entire system.

For proper selection of hardware, technology, preparation of emulsions and other liquids there is a need for a common criterion for evaluation of effectiveness of such plants $[14,21]$. 
Let's make the analysis of specific features of processing and distribution of energy in rotating hydrodynamic units (RGDU) of various designs. For this purpose the hydrodynamic systems, which are used for processing of liquids, are divided into four groups.

1. Disintegrators that perform impact effect on the fluid medium by rotating elements.

2. Hydrodynamic devices for acceleration of work fluid in rotor channels with subsequent fluid supply to special structural elements.

3. Hydrodynamic devices with alternating rotating and fixed openings in the form of slits or holes.

4. Devices in which hydrodynamic impact occurs in narrow annular gaps between the rotor and the stator, both having dents and projections of different form.

Of course, this division is arbitrary, since many RGDUs include a combination of elements from different groups. But we shall use this classification for analysis of design features of the working area. Names of devices in the sources of information may be different, depending on the authors' choice, but we shall consider them according to the principle of their operation.

The principle of the disintegrator is based on the impact of working bodies on the processed fluid medium during rotation of elements of different configurations with large angular velocities. Here processed fluid medium impacts against the surface of the fingers, teeth, plates or other protrusions takes place. Fig. 2 shows a disintegrator with two rotors, rotating toward each other. Processed fluid medium is fed through the charge channel 1 in the working area with rotors 2 arranged in the housing 3 . These plants typically use two electric motors 4. In this design cylindrical fingers are installed on the rotors. It is believed that the maximum kinetic energy achieved by counter-collisions at high velocities.
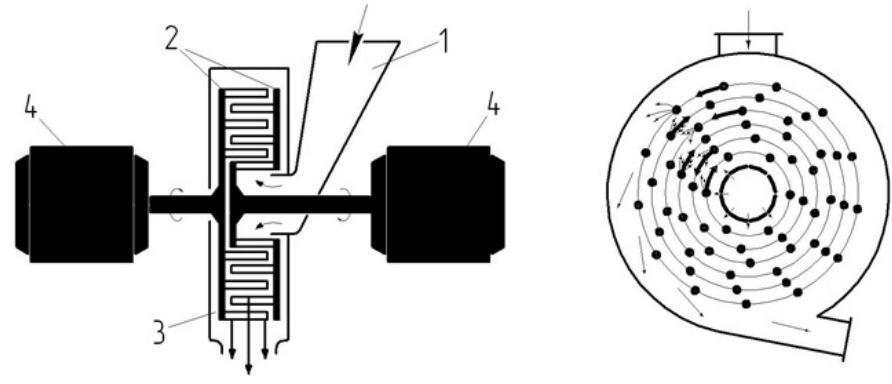

Fig. 2 Disintegrator design: 1 - charge channel, 2 - rotor, 3 - housing, 4 - electric motor

In such plants there occurs intense mixing, grinding, dispersion, mechanical activation, but there is no significant heating in them, which indicates a lack of energy dissipation, i.e. conversion of mechanical energy into heat.

In hydrodynamic rotating apparatuses of the second group fluid acceleration is performed in radial or in different by form channels of the rotor with subsequent delivery of the liquid to structural elements that produce various effects on the environment.

These include [22] the plant (see Fig. 3), in which acceleration of liquid is carried out in closed radial channels of rotor 2 , with further access to the cavitation elements 3. The kinetic energy of fluid motion is spent on creation a working pressure at the outlet 4 and on overcoming resistance in working area 1 . In such plants, when installing seals, virtually there is no return of the processed working fluid at the input of the rotor.

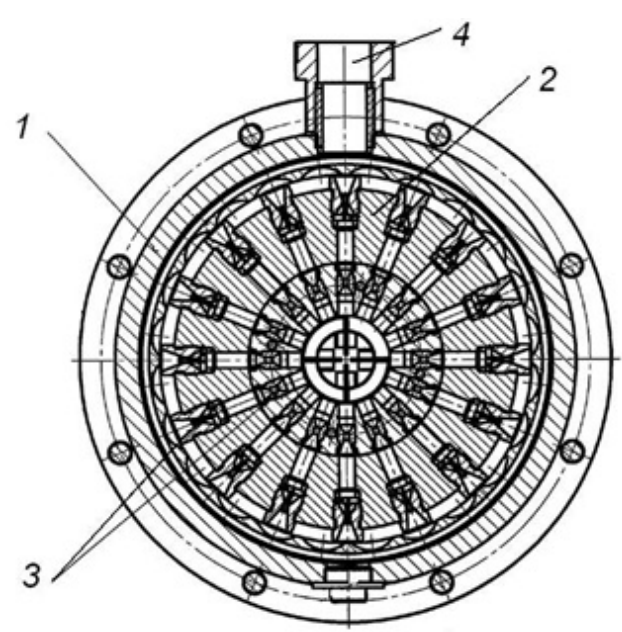

Fig. 3 Working area of the first class plant (RCA-03): 1 - working area, 2 - rotor, 3 - cavitation elements, 4 - outlet from working area

To the third group can be listed the rotary-pulsation apparatus (RPA), rotary apparatus with modulation flow (RAMF) and rotary-impulse apparatus (RIA). In these plants the character of impact on the working fluid is different. It is conditioned by the design feature of working elements - i.e. alternating fixed and rotating cylinders or cones with perforation in the form of slots or holes.

In this case, the impact on the working fluid is provided by forced closing of channels to flow in the rotating rotor and a fixed stator $[14,21]$. In this case, small gaps in coupling of working elements, except for the cavitation impact, there appears considerable compressive, shear stress, pressure pulsations and flow velocity in the fluid medium, which intensifies process.

Fig. 4 shows the RPA [14], with separate input 4, components to be mixed and dispersed. Case 1 covered by lid 2. On the shaft 8 mounted blades 3 to accelerate the liquid. Stator 5 is fixed on the case, against which rotor 9 rotates. Finished fluid medium runs through channel 6 .

Hydrodynamic plants of the second and third groups are flow type, and except for the dispersing impact additionally have pumping qualities. Besides the appearance of dissipative forces-friction there occurs heating of processed fluid medium.

To the fourth group can be assigned the apparatuses in which liquid medium moves through a narrow annular gap of variable cross-section. In this case, the rotor and the stator have grooves 


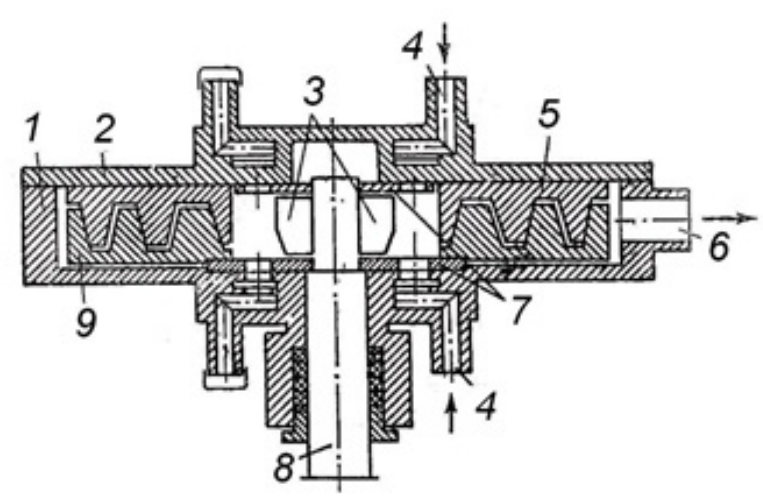

Fig. 4 Rotor-pulsation apparat: 1 - case, 2 - lid, 3 - blades, 4 - separate input, 5 - stator, 6 - channel for finished fluid medium, 7 - plates, 8 - shaft, 9 - rotor

and protrusions or other elements of various configurations. In this working area pressure pulsation and cavitation occur. Due to small gaps and high rotor speed the liquid medium is exposed to great shear stress created by liquid layers movement. It is in this gap that dissipation of energy with intensive heating of the liquid medium takes place. Such devices in addition to solving various technological problems can be used for heating of different heat-transfer liquids.

Fig. 5 shows the work area of a heat-generator "Tornado" type [23]. Liquid medium enters the end clearance on one side of the rotor and comes out from the other side (in Fig. 5 it is shown by arrows). Heating of liquid medium occurs due to friction and cavitational effects in the gap between the rotor and the stator. Usually, energy inputs for delivery of liquid medium are negligible as the consumption is small.

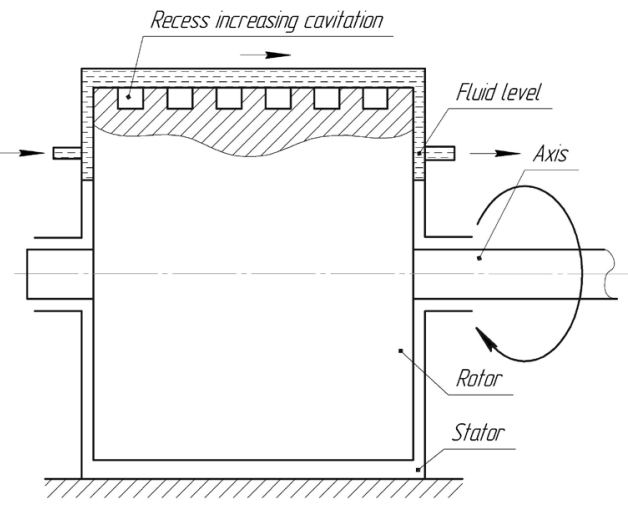

Fig. 5 Diagram of heat generator "Tornado" type

The most convenient parameter, determining the level of impact on the medium is the amount of energy spent on the process and its distribution in the apparatus [24, 25]. In this system kinetic energy of motion of fluid during rotation of rotor in addition to creating the hydraulic pressure at the output of the plant is converted into heat and change of physical-chemical state of the working fluid. Energy dissipation occurs due to resistance forces in the working area of the disperser, and depends on the design elements of the Working Zone and treatment regimes.

\subsection{Authors and affiliations}

Let's consider the structural diagram of energy consumption in the RPA (Fig. 6). Energy consumed by the drive of the RPA from the network $\left(\mathrm{W}_{\mathrm{ed}}\right)$ enlarged can be divided into two streams. The first $\left(\mathrm{W}_{\mathrm{pw}}\right)$ - is the energy loss in electromotor and in the mechanisms of the plant. These losses are determined by the power of idle run without filling the apparatus with working fluid.

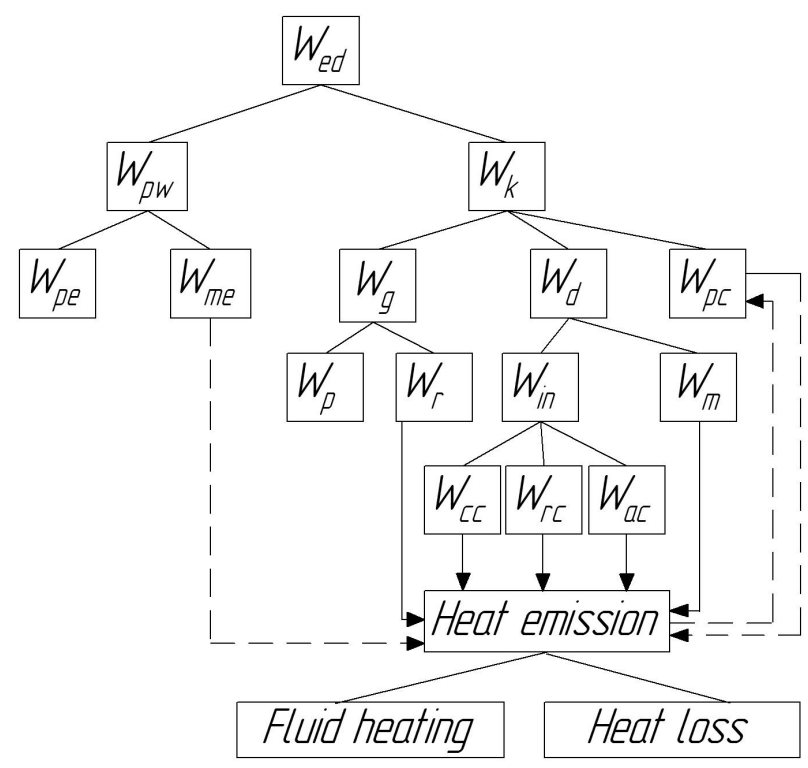

Fig. 6 The structure of energy distribution in the RPA

The second stream $\left(\mathrm{W}_{\mathrm{k}}\right)$ - is the kinetic energy of moving fluid, which, in turn is separated into the hydraulic $\left(\mathrm{W}_{\mathrm{g}}\right)$ and dissipation $\left(\mathrm{W}_{\mathrm{d}}\right)$ and the energy spent on change the physicochemical state of the working fluid $\left(\mathrm{W}_{\mathrm{pc}}\right)$. The quantity of hydraulic energy is determined by the pressure of the fluid at the outlet of the plant $\left(\mathrm{W}_{\mathrm{p}}\right)$ and the energy spent on flow return in the working grooves of the "rotor-stator" system $\left(\mathrm{W}_{\mathrm{r}}\right)$. Energy dissipation $\left(\mathrm{W}_{\mathrm{d}}\right)$ is spent on cavitation, dispersion, mixing $\left(\mathrm{W}_{\mathrm{m}}\right)$ and the internal loss $\left(\mathrm{W}_{\text {in }}\right)$, which include fluid friction in the inter cylinder clearance $\left(\mathrm{W}_{\mathrm{cc}}\right)$, disk friction in the radial $\left(\mathrm{W}_{\mathrm{rc}}\right)$ and axial $\left(\mathrm{W}_{\mathrm{ac}}\right)$ gaps between the rotor and the housing [3]. In the working area on the plant there occurs heat emission which is carried away by the flow, as well as the transition to structural elements and the environment. Fluid heating is influenced by the mechanical loss and return of fluid, but their contribution is negligible. When you change the physicochemical state of working fluid $\left(\mathrm{W}_{\mathrm{pc}}\right)$ heat can be emitted and absorbed.

Redistribution of energy in the plant occurs when parameters of the working zone (gap) and parameters of the fluid flow in both performance and pressure (rarefaction). In addition, the working fluid at the plant outlet can change its physical and chemical condition, which is determined depending on the technological conditions (requirements) of treatment.

In the plants of the second group, during processing of a certain liquid with constant rotor speed, internal losses $\left(\mathrm{W}_{\mathrm{in}}\right)$ vary 
slightly. In the RPA (the third group) changing of gap between the rotor and the stator substantially affects the resistance in the working area, which affects the redistribution of energy. In both cases, the dynamics of the thermal processes is mainly dependent on the energy dissipation $\left(\mathrm{W}_{\mathrm{d}}\right)$.

\subsection{Calculation of plant efficiency by energy parameters}

Electric losses in the motor $\left(N_{e d}\right)$ and in the plant mechanisms $\left(N_{m p}\right)$, that are defined by the idle power $\left(N_{f r}\right)$ without filling the plant with the work medium, should be taken into account when analyzing power inputs.

$$
N_{f r}=N_{e d}+N_{m p}
$$

Here, the effective power $\left(N_{e f}\right)$ is separated from the total cost $\left(N_{e d}\right)$.

$$
N_{f r}=N_{e d}-N_{m p}
$$

Flow energy at the plant outlet is determined by the hydraulic power depending on $Q$ flow rate and pressure $P$ in the work liquid bleed channel.

$$
N_{g}=Q \cdot p
$$

Depending on the working area structure, internal losses may include energy losses on return flow and friction losses in the end gaps and on other surfaces that do not directly affect the fluid medium.

The process intensity in the working area can be indirectly estimated by transition of a part of input energy into dissipative energy. Actual power inputs for heating of fluid passing through the dispersant are determined by the equation:

$$
N_{t}=K_{p} \cdot Q \cdot\left(T_{2}-T_{1}\right) \cdot T_{c} \cdot \rho .
$$

where $Q-$ is a flow rate through the dispersant (cum $/ \mathrm{h})$, $T_{1}$ and $T_{2}$ - fluid temperature at inlet and outlet of dispersant $\left({ }^{\circ} \mathrm{C}\right) ; T_{c}$ - heat capacity of working fluid $\left(\mathrm{kcal} / \mathrm{kg} \cdot{ }^{\circ} \mathrm{C}\right)$ - liquid density $(\mathrm{kg} / \mathrm{cum}), K_{p}-$ is the coefficient of correspondence of dimensions.

When using this method, we have singled out only the power that is used for hydrodynamic impact $N_{g}$ out of total plant power inputs. Then, the evaluation of effectiveness of thermal characteristics of hydrodynamicly processed work fluid can be done by the rate of heat release

$$
E_{t}=\frac{N_{t}}{N_{g}} .
$$

In practice, when testing hydrodynamic activators such components as idle power $N_{f r}$ and hydraulic power $N_{g}$ can be identified quite easily. Then, the energy conversion factor during heat emission with a slight error can be presented as:

$$
E_{e f}=\frac{N_{t}}{N_{e f}-N_{g}} .
$$

When performing comparative analysis of hydrodynamic systems for fluid activation, the assessment of their effectiveness (by the level of energy conversion) should also be done by the specific dissipation energy. I.e. the energy used for heat emission per volume unit when fluid medium passes through the unit

$$
W_{g}=\frac{N_{t}}{Q}(k W t h / \text { cum }) .
$$

While optimization the process of hydrodynamic treatment, it is important to determine the level of energy impact on the liquid medium, which is a background for necessary conversions ensuring the required physicochemical parameters of the fluid medium. Therefore, when evaluating the performance of the plant both energy parameters and parameters characterizing the ultimate condition of the fluid medium or process parameters should be considered. When designing and introducing apparatuses for hydrodynamic and cavitational impact one should consider technological, economic, environmental and other aspects of their operation.

In heat-generators "Tornado" type [23], energy distribution is somewhat different. The main resistance is in the radial gap; here the energy dissipation will take place.

In this case, at a certain diameter of the rotor and a fixed rotation frequency the intensity of heating is determined by the geometry profile on the cylindrical surface of the rotor and the magnitude of the gap. Both resistance and cavitation in the gap are relatively redistributed, determining the intensity of heat emission. In this design boiler energy input for supply of fluid is negligible, because the consumption is inconsiderable. Electrical and mechanical losses are defined similarly to the previous cases, by the power of idle run. Calculated dependence will be the same as in the analysis of the above plants.

\section{Experimental research of the developed construction for determining the optimal operating conditions}

To conduct hydrodynamic testing of plants an automated monitoring system was developed.

The methodology of the tests included determination of hydrodynamic parameters at operating plant. Thus, the information from sensors was entered into the computer. These data were formed in the table with a preset discreteness, which allowed analyzing of the effect of varying parameters on the power input.

To determine the optimal operating conditions of the dispersant an experimental study was done, on the basis of which the coefficients were determined that determined energy parameters of the process.

As an example, let's consider testing of dispersant DF-10A. The design of the dispersant belongs to the second group. Acceleration of work fluid is attained in the rotor channels with outlet to elastic blades where hydrodynamic fluctuations are 
transformed into acoustic ones. The intensity of cavitational impact on the work fluid is defined by the parameters of the flow through the elements of the working area.

The test was carried out during operation in the loop system closed to the tank (Fig. 7). Temperature measurements were made at the input (T1), at the output (T2), in the recirculation loop (T3) and in the tank (Tc). Pressure measurements (negative pressure) were made at the inlet (P1), at the outlet (P2), and pressure in recirculation loop (P3). Motor load was measured by current (I). Fluid flow rate measurements were made at the output (Q1) and in the recirculation loop (Q2).

For testing of the dispersant a scheme with fluid recirculating from output to input was used. Changing of hydrodynamic parameters was made by closing the shutdown valve (S2).

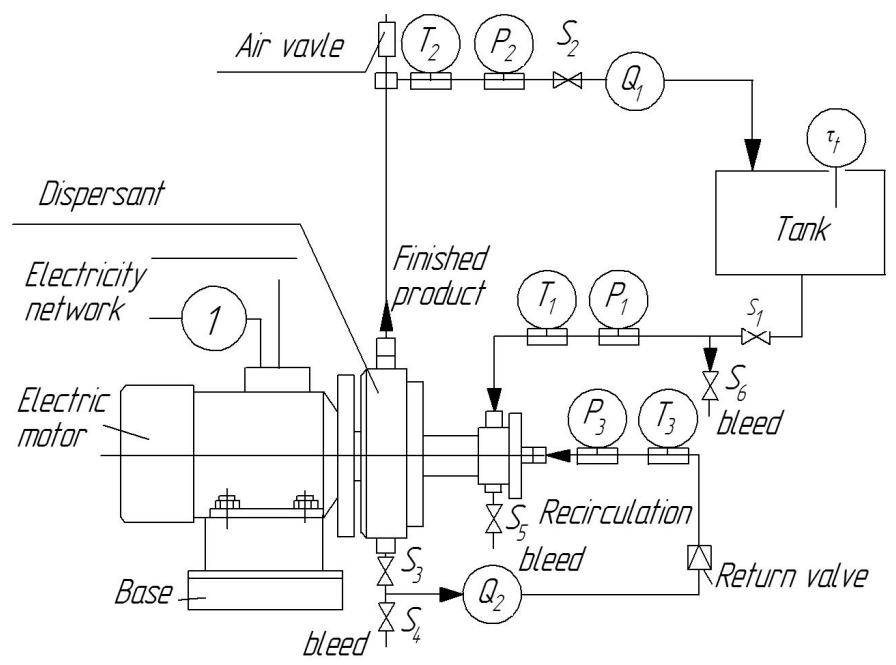

Fig. 7 DF-10A Test Measurements Diagram

\section{Experimental results and discussion}

As an example, let's consider processing of waterfuel oil mixture with water content $8 \%$ in dispersant DF-10A $\left(N_{\text {nom }}=11 \mathrm{kWt}\right)$. Electric motor power requirement made $N_{e d}=8.4 \mathrm{kWt}$, power losses of idling motor $N_{f r}=3.2 \mathrm{kWt}(38 \%)$. Negative pressure at the dispersant inlet $P 1=-0.01 \mathrm{MPa}$; outlet pressure $P 2=0.11 \mathrm{MPa}$, flow rate at the outlet was $Q 1=2.25 \mathrm{cum} / \mathrm{h}$, flow rate in the recirculation circuit $Q 2=1.2 \mathrm{cum} / \mathrm{h}$. Temperature difference between the inlet and outlet was $\Delta T=11^{\circ} \mathrm{C}$.

Calculation of energy performance made by the formulas given in Section 2.3, revealed the following. Hydraulic power $N_{g}=0.71 \mathrm{kWt}(8.4 \%)$. When running on the recycling circuit, that takes into account merging of heat flows and flow rate at the outlet, the power of hydrodynamic effect makes $N_{t}=10.76 \mathrm{kWt}$. The coefficient of thermal load $K_{t}=2.07$. Specific energy needed for hydrodynamic effect made $W_{t}=4.78 \mathrm{kWt} \mathrm{h} / \mathrm{cum}$.

The resulting water-fuel oil emulsion had dispersion in the range of 0.5 to 5 microns. Test for resistance showed that disintegration was not observed during three months.

For further optimization of processing parameters for each composition of water-fuel oil emulsion a comparison of the received and the required physicochemical condition of the emulsion with specific energy, used for hydrodynamic impact, shall be done.

\section{Conclusions}

In this paper the main directions of effective preparation and use of water fuel emulsions have been proposed. Efficient use of such fuels as shale oil depends on the applied equipment. Rational choice of equipment for processing water-fuel emulsions has been theoretically substantiated. The proposed methodology is based on a comparison of energy consumption in the working area of the hydrodynamic cavitation plant, allows to perform the analysis of hardware and technologies for manufacturing of mixtures by the intensity of impact on the processed working fluid.

Analysis of the above systems of cavitation process enables us to conclude that in each case the choice of cavitation impact on the liquid working fluid and the appropriate hardware must be properly justified.

\section{References}

[1] Oyewunmi, O. A., Kirmse, C. J. W., Pantaleo, A. M., Markides, C. N. "Performance of working-fluid mixtures in ORC-CHP systems for different heat-demand segments and heat-recovery temperature levels." Energy Conversion and Management. 148, pp. 1508-1524. 2017. https://doi.org/10.1016/j.enconman.2017.05.078

[2] Becht, S., Franke, R., Geißelmann, A., Hahn, H. "An industrial view of process intensification." Chemical Engineering Processing: Process Intensification. 48(1), pp. 329-332. 2008.

https://doi.org/10.1016/j.cep.2008.04.012

[3] Kashid, M. N., Renken, A., Kiwi-Minsker, L. "Influence of Flow Regime on Mass Transfer in Different Types of Microchannels." Industrial \& Engineering Chemistry Research. 50(11), pp. 6906-6914. 2011. https://doi.org/10.1021/ie102200j

[4] Vardanega, R., Santos, D. T., Meireles, M. A. A. "Intensification of bioactive compounds extraction from medicinal plants using ultrasonic irradiation." Pharmacognosy Review. 8(16), pp.88-95. 2014. https://doi.org/10.4103/0973-7847.134231

[5] Mohod, A. V., Gogate, P. R., Viel, G., Firmino, P., Giudici, R. "Intensification of biodiesel production using hydrodynamic cavitation based on high speed homogenizer." Chemical Engineering Journal. 316, pp. 751-757. 2017.

https://doi.org/10.1016/j.cej.2017.02.011

[6] Li, P., Song, Y., Yu, S., Park, H.-D. "The effect of hydrodynamic cavitation on Microcystis aeruginosa: Physical and chemical factors." Chemosphere. 136, pp. 245-251. 2015.

https://doi.org/10.1016/j.chemosphere.2015.05.017

[7] Freeman, J., Hellgardt, K., Markides, C. N. "Working fluid selection and electrical performance optimisation of a domestic solar-ORC combined heat and power system for year-round operation in the UK." Applied Energy. 186(3), pp. 291-303. 2017.

https://doi.org/10.1016/j.apenergy.2016.04.041

[8] Konstantinov, S. Y., Tselischev, V. A., Tselischev, D. V. "Analytical Calculation of Hydraulic Characteristics of Jet-cavitation Fluid Mass Flow Stabilizers." Procedia Engineering. 176, pp. 107-117. 2017. https://doi.org/10.1016/j.proeng.2017.02.278 
[9] Vij, V., Goyal, K. "A Novel Approach to Hybrid Abrasive-Cavitation Methods for Machining." European Journal of Advances in Engineering and Technology. 4(3), pp. 221-226. 2017. [Online]. Available from: http://www.ejaet.com/PDF/4-3/EJAET-4-3-221-226.pdf [Accessed: 12th December 2017]

[10] Guo, C., Zhu, X. "Effect of ultrasound on dynamics characteristic of the cavitation bubble in grinding fluids during honing process." Ultrasonics. 84, pp. 13-24. 2018.

https://doi.org/10.1016/j.ultras.2017.09.016

[11] Michael, T., Yang, J., Stern, F. "A sharp interface approach for cavitation modeling using volume-of-fluid and ghost-fluid methods." Journal of Hydrodynamics, Ser. B. 29(6), pp. 917-925. 2017. https://doi.org/10.1016/S1001-6058(16)60806-5

[12] Fedotkin, I. M., Nemchin, A. F. "spol'zovanie kavitacii v tehnologicheskih processah." (The use of cavitation in technological processes.) Vicha shkola, Kiev, Ukraine, 1984. (in Russian)

[13] Ivanov, V. M. "Toplivnye emul'sii." (Fuel emulsions.) The USSR AS, Moscow, Russia, 1962. (in Russian)

[14] Chervjakov, V. M., Judaev, V. F. "Gidrodinamicheskie i kavitacionnye javlenija $\mathrm{v}$ rotornyh apparatah." (Hydrodynamic and cavitation phenomena in rotor machines.) Mashinostroenie Publishers, Moscow, Russia, 2007. (in Russian)

[15] Mozgovoy, N. V., Voskovykh, V. I. "Uluchshenie ekologicheskih pokazateley rabotyi kotloagregatov metodom szhiganiya vodomazutnyih emulsiyt." (Improvement of ecological indexes of working as of boilers method of incineration of water and fuel oil emulsions.) Bulletin of Voronezh State Technical University. 5(4), pp. 104-106. 2009. (in Russian)

[16] Akchurin, R. J., Balahnichev, N. A. "Podgotovka mazuta k szhiganiju v kavitacionnom reaktore." (Preparation of fuel oil for combustion in a cavitation reactor.) Energetik. 9, pp. 8-9. 1986. (in Russian)

[17] Khan, M. Y. Abdul Karim, Z. A., Hagos, F. Y., Aziz, A. R. A., Tan, I. M. "Current Trends in Water-in-Diesel Emulsion as a Fuel." The Scientific World Journal. 2014, pp. 1-15. 2014. https://doi.org/10.1155/2014/527472

[18] Korjagin, V. A. "Szhiganie vodotoplivnyh emul'sij i snizhenie vrednyh vybrosov." (Burning water fuel emulsions and reducing harmful emissions.) Nedra Publishers, Moscow, Russia, 1995. (in Russian)
[19] Nikishina, J. G. "Razrabotka apparatov, napravlennyh na ohranu prirody pri ispol'zovanii zhidkogo uglerodnogo topliva." (Development of devices aimed at protecting nature using liquid hydrocarbon fuel.) Bulletin TISBI. 2, pp. 213-219. 2004. (in Russian)

[20] Syu, J.-Y., Chang, Y.-Y., Tseng, C.-H., Yan, Y.-L., Chang, Y.-M., Chen, C.-C., Lin, W.-Y. "Effects of water-emulsified fuel on a diesel engine generator's thermal efficiency and exhaust." Journal of the Air \& Waste Management Association. 64(8), pp. 970-978. 2014. https://doi.org/10.1080/10962247.2014.905508

[21] Ferrari, A. "Fluid dynamics of acoustic and hydrodynamic cavitation in hydraulic power systems." Proceedings of the Royal Society A, Mathematical, Physical and Engineering Sciences. 473(2199), pp. 1-32. 2017. https://doi.org/10.1098/rspa.2016.0345

[22] Fesenko, A. V. "Method for estimating the parameters of cavitation processing of a lubricating coolant." Bulletin of National Technical University of Ukraine "KPI". 23, pp. 43-48. 2008.

[23] Posmetnyj, B. M., Gorpinko, J. I. "Sverh'edinichnyie teplogeneratoryi rotornyih konstruktsiy: poluchenie para i novyie fizicheskie effektyi." (Superunit heat generators of rotor structures: steam generation and new physical effects.) In: The Scientific and Technical Conference "Abnormal physical phenomena in the energy sector and prospects for the creation of non-traditional energy sources (energy-2005)", Kharkov, Ukraine, June 15-16, 2005, pp. 268-277. (in Russian)

[24] Fesenko, A. V. "Sravnitelnyiy analiz gidrodinamicheskih ustanovok dlya dispergirovaniya, gomogenizatsii i nagreva zhidkosti." (Comparative analysis of hydrodynamic installations for dispersion, homogenization and heating of a liquid.) Bulletin of the Sumy State University. Series of Engineering Sciences. 4, pp. 103-109. 2009. (in Russian)

[25] Yi, H., Wang, Y., Smith, K. H., Fei, W. Y., Stevens, G. W. "CFD Simulation of Liquid-Liquid Two-Phase Hydrodynamics and Axial Dispersion Analysis for a Non-Pulsed Disc and Doughnut Solvent Extraction Column." Solvent Extraction and Ion Exchange. 34(6), pp. 535-548. 2016. https://doi.org/10.1080/07366299.2016.1226025 